\title{
Small bowel obstruction due to anomalous congenital peritoneal bands - case series in adults
}

\author{
Sozen $\mathrm{S}^{1}$, Emir $\mathrm{S}^{2}$, Yazar $\mathrm{FM}^{2}$, Altinsoy $\mathrm{HB}^{3}$, Topuz $\mathrm{O}^{4}$, Vurdem $\mathrm{UE}^{5}$, Tukenmez $\mathrm{M}^{4}$, \\ Keceli $\mathbf{M}^{4}$, Uzun $\mathrm{AS}^{6}$, Cetinkunar $\mathrm{S}^{6}$, Ozkan $\mathrm{Z}^{6}$, Guzel $\mathrm{K}^{7}$
}

Adana Numune Training and Research Hospital, General Surgery, Adana, Turkey. selimsozen63@yahoo.com

\begin{abstract}
Background: Congenital bands cause $3 \%$ of all intestinal obstruction and almost always lead to small bowel obstruction. In adults, obstruction due to bands is even rarer.

Materials and methods: A multicenter study in Turkey. From January 2000 to December 2010 inclusive - a period of 10 years - all adult patients admitted to the emergency departments with a clinical diagnosis of acute intestinal obstruction due to congenital peritoneal band were included in the study. Surgery was defined as emergency. Recorded operative findings included the site of obstruction, and the operative procedure to relieve it. In the present study, the findings in adult patients with congenital band reported in the literature together with findings in ten cases operated at four center were retrospectively assessed with respect to their demographic, preoperative, peroperative, and postoperative characteristics.

Results: There were 8 males and 2 females aged between 18 and 72 year. There were no history of abdominal or inguinal surgery. Plain abdominal X-rays radiography revealed air- fluid levels in all patients. All the bands were ligated and divided. On histopathological examination, the bands were composed of loose connective tissue containing blood vessels. There were no calcification in the bands.

Conclusion: an anomalous congenital band could be included in the differantial diagnosis of intestinal obstruction. This clinical situation requires early surgical intervention that will be diagnostic and therapeutic (Tab. 1, Fig. 4, Ref. 21). Full Text in PDF www.elis.sk.

Key words: small bowel obstruction, anomalous congenital peritoneal bands.
\end{abstract}

Intraabdominal adhesion and peritoneal bands are seen mostly seconder to the operations (1) and cause to several clinical problems like first of all intestinal obstruction, atipical abdominal pain, intestinal dysfunction, Congenital bands cause $3 \%$ of all intestinal obstruction and almost always lead to small bowel obstruction (2). In adults, obstruction due to bands is even rarer.

Such bands cause obstruction by entrapment of the intestine between the band and mesentery or by compression of the bowel (3). However, it is possible that these bands lead to an internal herniation.

\section{Materials and methods}

From January 2000 to December 2010 inclusive - a period of 10 years - all adult patients admitted to the emergency departments with a clinical diagnosis of acute intestinal obstruction due

${ }^{1}$ Adana Numune Training and Research Hospital, General Surgery, Adana, Turkey, ${ }^{2}$ Elazig Training and Research Hospital, General Surgery, Elazig, Turkey, ${ }^{3}$ Elazig Training and Research Hospital, Radiology Department, Elazig, Turkey, ${ }^{4}$ Kayseri Training and Research Hospital, General Surgery, Kayseri, Turkey, ${ }^{5}$ Kayseri Training and Research Hospital, Radiology Department, Kayseri, Turkey, ${ }^{6}$ Adana Numune Training and Research Hospital, General Surgery, Adana, Turkey, and ${ }^{7}$ Carsamba Government Hospital, General Surgery, Samsun, Turkey

Address for correspondence: Selim Sozen, MD, Adana Numune Training and Research Hospital Department of General Surgery, Yurt mahallesi 71335 sokak. 13/19 Irfan Altas apt. Cukurova, Adana, Turkey. to congenital peritoneal band were included in the study. Patients diagnosed as incarcerated or irreducible hernia were excluded.

The name, age and sex of each patient were re-corded on a special prepared chart. The onset, du-ration, and main symptoms of obstruction, as well as the past medical history, x-ray and operative findings were also recorded. Findings on plain abdominal radiolgraphs and later at operation con-firmed the diagnosis. Once the clinical diagnosis of obstruction was con-firmed with plain abdominal $\mathrm{x}$-rays the initial treatment comprising nasogastric decompression, intravenous crytalloids, bladder catheterization, antibiotics and adequate analgesics was started.

Surgery was defined as emergency. Recorded operative findings included the site of obstruction, and the operative procedure to relieve it. In the present study, the findings in adult patients with congenital band reported in the literature together with findings in ten cases operated at four center were retrospectively assessed with respect to their demographic, preoperative, peroperative, and postoperative characteristics.

\section{Results}

There were 8 males and 2 females aged between 18 and 72 year. Physical examination data were evaluated individually. All patients had abdominal pain. 5 patients had naused and vomiting. 8 patients had distension, 2 patients had timpanism. There was a palpable mass in 3 patients. It was seen that in rectal examination for 8 patients there was nothing in ampulla. 8 patients consulted 

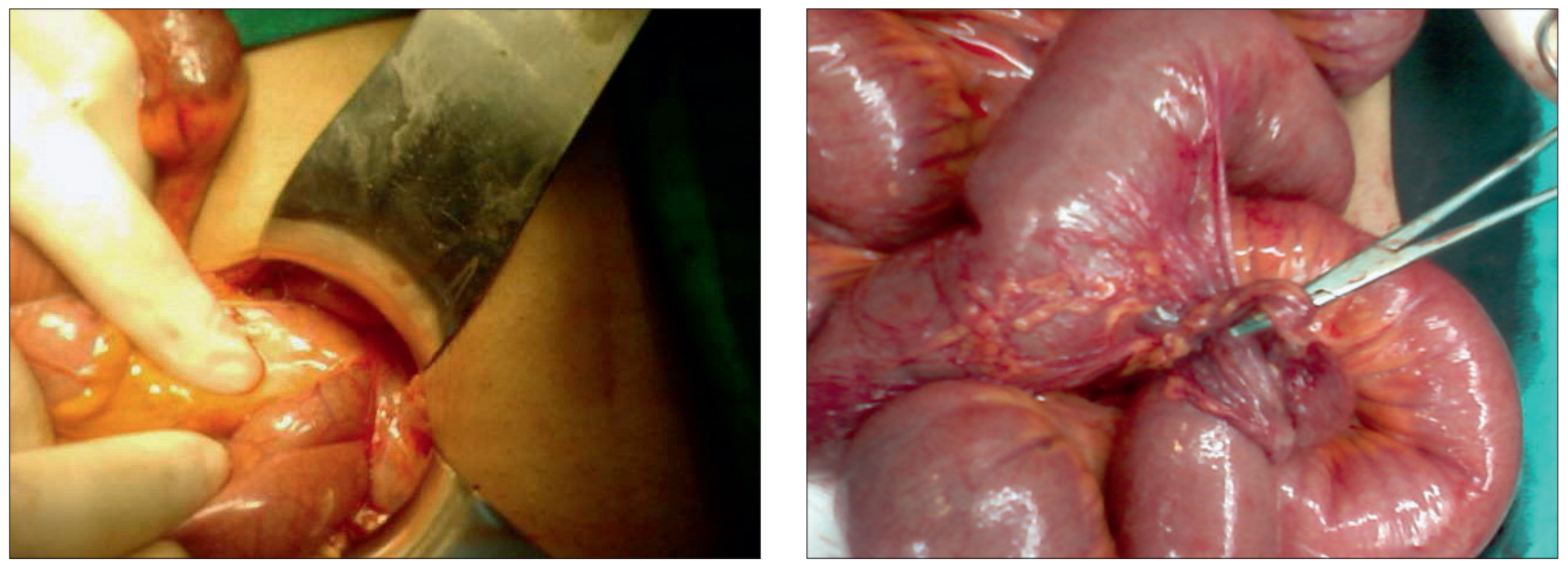

Figures 1 and 2. Bands were located between ascending colon and terminal ileum or to the terminal ileum mesentery.

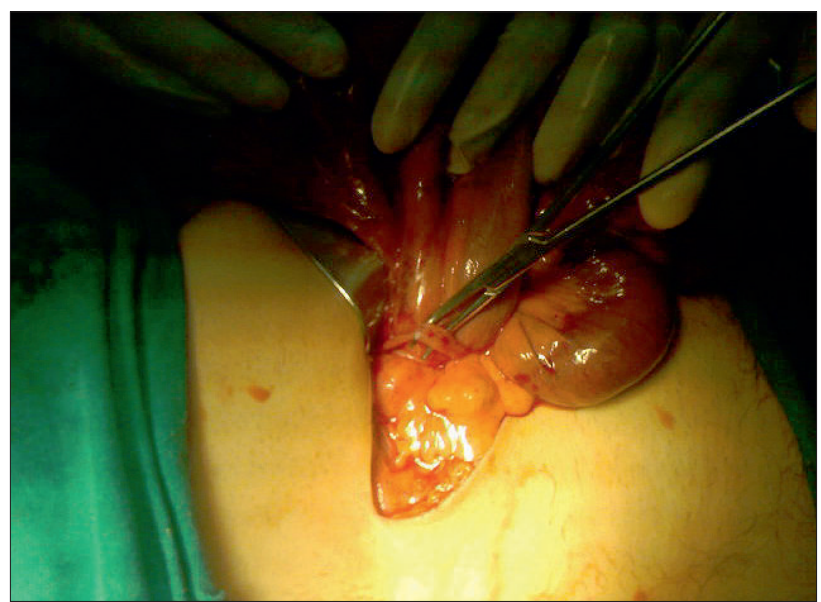

Fig. 3. Bands were located between jejunum to jejunum.

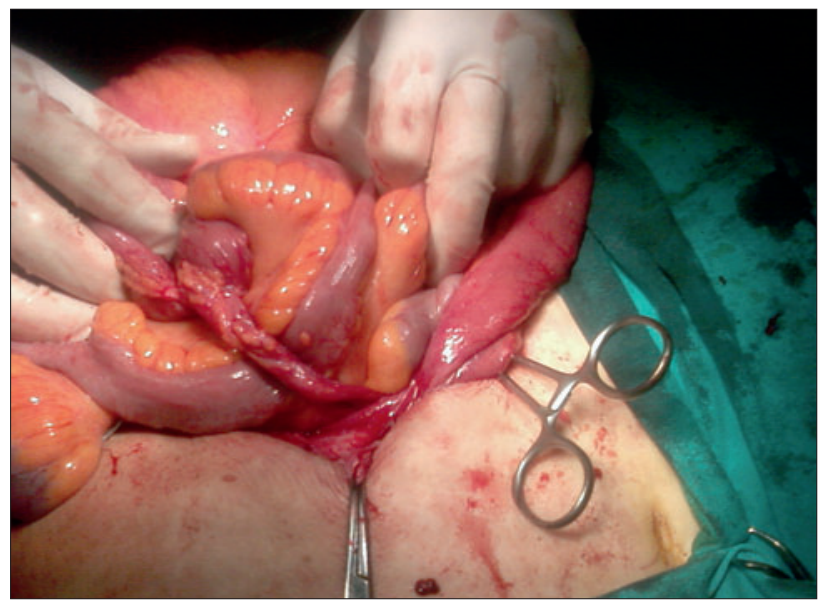

Fig. 4. Fibrous connection of the ileum to the umbilicus, and Meckel's diverticulum.

to hospital for their first bowel obstruction attack while 2 patients had bowel obstruction attack previously. 6 patients were operated on account of acute abdominal syndrome. The mean of these patients had the operation was 0.8 days. 3 patient were operated on account of bowel obstruction. The rest of the patients had the operation was 3.35 days.

There were no history of abdominal or inguinal surgery. Plain abdominal X-rays radiography revealed air- fluid levels in all patients. Preoperative abdominal ultrasonography was performed in all patients,all of whom showed dilated small intestinal segments. Preoperative CT was performed. A contrast enhanced computed tomography scan (CECT) of abdomen revealed progressive dilatation of small bowel segments.

At laparotomy, one of the terminations of the bands were located between ascending colon and terminal ileum or to the terminal ileum mesentery in 4 patients (Figs 1 and 2) The other end of the bands were located between jejunum to jejunum in 2 cases (Fig. 3), the Treitz' ligament to terminal ileum in one case, omphalomesenteric duct cyst, fibrous connection of the ileum to the umbilicus, and Meckel's diverticulum in 2 cases (Fig. 4), Ladd's bands in one case were found (Tab. 1). All the bands were ligated and divided. On histopathological examination, the bands were composed of loose connective tissue containing blood vessels. There were no calcification in the bands.

Two patient required bowel resection. Late hospitalization was considered to be an important factor when determining the need for resection.

No early postoperative complications occurred, and patients were discharged home after 1 to 5 postoperative days (mean, 2 days). Patients were followed up for 3 months to 16 months.

\section{Discussion}

Congenital bands are a rare cause of intestinal obstruction in infancy and childhood. Their occurrence in adults is an extremely rare condition $(3,4)$.

Touloukian was the first to describe about congenital bands causing small bowel obstruction in significant detail $(3,5)$.

Congenital bands present as intestinal obstruction occurring mostly in children at known anatomical sites such as Meckels diverticulum, ligament of Trietz and remnants of vitelline duct $(3,5)$. The obstructions mainly localized to the terminal ileum and colon $(3,5,6)$. 
Tab. 1. Ladd's bands.

\begin{tabular}{|c|c|c|c|c|c|c|}
\hline Case no & Age & Gender & $\begin{array}{c}\text { White blood } \\
\text { cell } / \mathrm{mm}^{3}\end{array}$ & $\begin{array}{l}\text { Aplication } \\
\text { time to } \\
\text { hospital (h) }\end{array}$ & Localization & Treatment \\
\hline 1 & 22 & $\mathrm{M}$ & 13000 & 6 & between ascending colon and terminal ileum & Simple band resection \\
\hline 2 & 18 & $\mathrm{M}$ & 11800 & 8 & between ascending colon and terminal ileum & Simple band resection \\
\hline 3 & 33 & $\mathrm{~F}$ & 24000 & 26 & between ascending colon and terminal ileum & $\begin{array}{l}\text { Simple band resection and small } \\
\text { bowel resection }\end{array}$ \\
\hline 4 & 54 & $\mathrm{M}$ & 7800 & 18 & between ascending colon and terminal ileum & Simple band resection \\
\hline 5 & 44 & $\mathrm{M}$ & 8700 & 22 & jejuno-jejuno congenital band & Simple band resection \\
\hline 6 & 72 & $\mathrm{M}$ & 14000 & 6 & jejuno-jejuno congenital band & Simple band resection \\
\hline 7 & 38 & $\mathrm{M}$ & 6800 & 18 & Treitz' ligament to terminal ileum & Simple band resection \\
\hline 8 & 27 & $\mathrm{M}$ & 23000 & 9 & $\begin{array}{l}\text { fibrous connection of the ileum to the umbilicus, } \\
\text { and Meckel's diverticulum }\end{array}$ & Simple band resection \\
\hline 9 & 32 & $\mathrm{M}$ & 12000 & 8 & $\begin{array}{l}\text { fibrous connection of the ileum to the umbilicus, } \\
\text { and Meckel's diverticulum }\end{array}$ & Simple band resection \\
\hline 10 & 66 & $\mathrm{~F}$ & 19000 & 8 & Ladd's bands & $\begin{array}{l}\text { Simple band resection and Ladd pro- } \\
\text { cedure. And small bowel resection }\end{array}$ \\
\hline
\end{tabular}

$\mathrm{M}$ - male, $\mathrm{F}$ - female.

Its localization excluded known embryogenic remnants, such as vitelline arteries or veins or omphalomesenteric ducts or mesourachus. The most likely explanation is described by Akgur et al (3), is that this band originated from a mesenteric anomaly. At about the 28th day of intrauterine life, transiently, the dorsal and ventral mesenteries divide the peritoneal cavity into right and left halves, but the ventral mesentery soon disappears, except around the liver and in front of the stomach (7).

As the intestines assume their final positions, their mesenteries are pressed against the posterior abdominal wall. Akgur et al (3) reported eight children of ACB, which was the largest series of children. A single thick band with blood vessels was found to be the cause of obstruction at laparotomy. One of the terminations of this band was attached to the terminal ileum or to the terminal ileum mesentery in all patients. The other end of the band was attached to the ascending colon in four cases, the Treitz' ligament in two cases, and the right lobe of the liver in two children (3). several locations have been described including rim of the iliac fossa to the sigmoid mesocolon (6), jejunum to jejunum (8), ileum to the sigmoid mesentery (9), root of the mesentery to jejunum $(10,11)$, terminal ileum to the mesoappendix (12) and Ladd's bands arising from the caecum going across the duodenum to the parietal peritoneum in the right hypochondrium.

Obstruction of the small bowel causes symptoms shortly after onset: abdominal cramps centered around the umbilicus or in the epigastrium, vomiting, and - in patients with complete obstruction - obstipation. Patients with partial obstruction may develop diarrhea. Severe, steady pain suggests that strangulation has occurred. In the absence of strangulation, the abdomen is not tender. Hyperactive, high-pitched peristalsis with rushes coinciding with cramps is typical. Sometimes, dilated loops of bowel are palpable. With infarction, the abdomen becomes tender and auscultation reveals a silent abdomen or minimal peristalsis. Shock and oliguria are serious signs that indicate either late simple obstruction or strangulation. Congenital bands cause and usually present with symptoms of bowel obstruction. Rarely, the presentation may be more suggestive of other conditions such as mesenteric infarction, perforated duodenal ulcer, diverticulitis, cholecystitis or strangulated hernia, and there are only two other reports of congenital bands presenting as appendicitis in a French article by Habib et al (4).Volvulus may also occur round an intraabdominal fibrotic or omental band or present as an isolated entity with axial rotation around a Meckel's diverticulum (7). Meckel's diverticulum is the most common end result of the spectrum of omphalomesenteric duct anomalies, which also include umbilico-ileal fistula, omphalomesenteric duct sinus, omphalomesenteric duct cyst, fibrous connection of the ileum to the umbilicus, and Meckel's diverticulum. Band extending between the diverticulum and the base of the mesentery, forming a loop in which a part of ileum may get stuck causing obstruction (13).

Midgut volvulus is rare in adults (14). Most acute presentations occur in the first month of life. In the adult with malrotation, midgut volvulus is the most common cause of bowel obstruction (15). Acute presentation is with volvulus of the midgut or ileocaecum occurring most frequently in the neonate, with the likelihood decreasing with age $(16,17)$. The chronic presentation is more challenging with symptoms including chronic abdominal pain, bloating, vomiting, constipation and diarrhoea all being reported (18). The pathophysiology of these chronic symptoms may relate to the compressive effects of peritoneal bands running from the caecum and ascending colon to the right lateral wall. The volvulus occurs around the primitive dorsal mesentery and thus constricts and compresses the superior mesenteric vessels; this process will particularly affect the venous drainage and the involved bowel will become stuffed with blood. The infarcted bowel will bleed into its lumen and if the volvulus is then relieved spontaneously the patient will pass bloodstained diarrhoea signifying the end of the attack.

The classic treatment for incomplete intestinal rotation is the Ladd procedure, which entails mobilization of the right colon, division of Ladd's bands and mobilization of the duodenum, division of adhesions around the SMA to broaden the mesenteric base, and an appendectomy. This procedure was originally described by Ladd (19). 
Patients usually present with symptoms of intestinal obstruction, and despite the availability and wide use of modern imaging techniques, preoperative diagnosis is very difficult to establish. Plain films are nonspecific. A simple abdominal x-ray and clinical examination might be sufficient and may prompt surgical exploration of a small bowel obstruction. The small bowel faeces sign found within dilated, obstructed loops was demonstrated in seven patients (63.6 \%). This finding is most often related to a SBO. Ultrasound scan might provide details of localized distended intestinal loops or indirect signs of peritonitis, but it is not specific while barium-contrast gastrointestinal series may provide clues to narrow the differential diagnosis. A CTscan of abdomen is also unlikely to detect a band. A diagnostic laparoscopy is a valuable aid to diagnosis and definitive management (20). The absence of caecal gas shadow or the localization of small intestinal loops predominately in the right side should arouse the suspicion of malrotation (19). Malrotation can be diagnosed on CT by the anatomic location of a rightsided small bowel, a left-sided colon and an abnormal relationship of the superior mesenteric vessels. Nichols and Li described the abnormal position of the superior mesenteric vein (SMV) wherein the SMV was situated to the left of the superior mesenteric artery (SMA) instead of to the right on CT scan in patients with malrotation (21).

In conclusion, this case demonstrates that an anomalous congenital band could be included in the differantial diagnosis of intestinal obstruction. This clinical situation requires early surgical intervention that will be diagnostic and therapeutic.

\section{References}

1. William A. Tito, Michael G. Sarr. Intestinal obstruksiyon. In: George Zuidema Shackelford's Surgery of the Alimentary Tract,WB Saunders 1996; 5: 375-416.

2. Perry JF, Smith A, Yonehiro EG. Intestinal obstruction caused by adhesions; a review of 388 cases. Ann Surg 1955; 142: 810.

3. Akgur FM, Tanyel FC, Buyukpamukcu N, Hicsonmez A. Anomalous congenital bands causing intestinal obstruction in children. J Pediatr Surg 1992; 27: 471-473.

4. Habib E, Elhadad A. Small bowel obstruction by a congenital band in 16 adults. Ann Chir 2003; 128: 94-97.

5. Touloukian R (1979) Pediatric surgery, Miscellaneous causes of small bowel obstruction. 3rd ed. Chicago (Ill)7 Year Book ; 961.

6. Lin DS, Wang NL, Huang FY, Shih SL. Sigmoid adhesion caused by a congenital mesocolic band. J.Gastroenterol 1999; 34: 626-628.
7. Moore KL (1982) The developing human, 3rd ed. Saunders: Philadelphia (Pa); 167-78, 227-254.

8. Itagaki MW, Lema R, Gregory JS. Small bowel obstruction caused by a congenital jejuno-jejuno band in a child. Pediatr Emerg Care 2005; 21: 673-674.

9. Barias E, Sezen O, Firuzan D, Mesut Y, Harun G. Anomalous congenital band: a rare cause of intestinal obstruction and failure to thrive. Pediatr Surg Int 2005; 21: 1018-1020.

10. Dimitrois C, George AA, Dimosthenis Z, Nikolas X. Intestinal obstruction due to an anomalous congenital band. Saudi J Gastroenterol 2008; 2008; 14: 36-37.

11. Liu C, Wu TC, Tsai HL, Chin T, Wei C. Obstruction of the proximal jejunum by an anomalous congenital band-a case report. J Pediatr Surg 2005; 40: E27-29.

12. Maeda A, Yokoi S, Kunou T, Tsuboi S, Niinomi N, Horisawa M, Bando E, Uesaka Intestinal obstruction in the terminal ileum caused by an anomalous congenital vascular band between the mesoappendix and the mesentry: Report of a case. Surg Today 2004; 34: 793-795.

13. Tomikswa M, Taomoto J, Saku M, Takeshita M: A loop formation of meckels diverticulum; a case with obstruction of the ileum, Turkish journal of trauma and emergency surgery. Ulus Travma Acil Cerrahi Derg 2003; 9: 134-136.

14. Pelucio M, HaywoodY. Midgut volvulus: an un usual case of adolescent abdominal pain. Am J EmergMed 1994; 12: 167-171.

15. GohiML, DeMeesteTrR.Midgut nonrotation in adults: an aggressiveapproach.Am J Surg 1975; 129: 319-323.

16. Prasil P, Flageole H, Shaw KS, Nguyen LT, Youssef S, Laberge JM. Should malrotation in children be treated differently according to age? J Pediatr Surg 2000; 35: 756-758.

17. Spigland N, Brandt ML, Yazbeck S. Malrotation presenting beyond the neonatal period. J Pediatr Surg 1990; 25: 1139-1142.

18. Seymour NE, Andersen DK. Laparoscopic treatment of intestinal malrotation in adults. JSLS 2005; 9: 298-301.

19. Ladd WE. Congenital obstruction of the duodenum in children. $\mathrm{N}$ Engl J Med 932; 206: 277-283.

20. Wu JM, Lin HF, Chen KH, Tseng LM, Huang SH. Laparoscopic diagnosis and treatment of acute small bowel obstruction resulting from a congenital band. Surg Laparosc Endosc Percutan Tech 2005; 15: 294-296.

21. Garg P, Singh M, Marya SK. Intestinal malrotation in adults. Indian J Gastroenterol 1991; 10: 103-104.

Received November 21, 2011. Accepted January 9, 2012. 